\title{
A IMPORTÂNCIA DO SETOR VAREJISTA NA COMERCIALIZAÇÃO DE FEIJÃO NO PARANÁ ${ }^{1}$
}

\author{
Paula Tissiany Carneiro ${ }^{2}$ \\ José Luiz Parré
}

\begin{abstract}
Resumo - Embasado em conceitos e modelos de "comercialização", este trabalho teve como objetivo analisar as transmissões de preços entre produtor, atacado e varejo da cadeia produtiva do feijão no estado do Paraná, no período de 1995/2003. Para isso, verificou-se como a variável preço foi transmitida entre os segmentos, estimando-se as margens e o sentido de causalidade entre os três setores de mercado, que, juntamente com a melhoria do produto final, servem como indicadores de eficiência na distribuição e comercialização do produto. De modo geral, o varejo causou variações nos preços ao produtor e atacado - causalidade confirmada pela aplicação do modelo VAR, mas que não representou uma tendência explosiva desta variável. O estudo revelou uma tendência de estabilidade no preço ao atacado, acompanhada de pequenos decréscimos, juntamente com o ganho de importância dos supermercados na distribuição de feijão ao varejo, garantindo a qualidade do produto final. A reestruturação vivida por este setor reflete o momento de estabilidade econômica ocorrido no país e o novo perfil do consumidor.
\end{abstract}

Palavras-chave: comercialização, transmissão de preços, feijão, Paraná.

Recebido em 29/04/2005

Aceito em 02/06/2005

2 Economista formada pela UFV, mestre em Teoria Econômica pela Universidade Estadual de Maringá, Professora Auxiliar do Departamento de Economia do Centro Universitário Franciscano/UNIFRA. E-mail: paula.t@ pop.com.br

3 Professor Adjunto do Departamento de Economia da Universidade Estadual de Maringá, Professor do Programa de Mestrado em Economia/UEM. E-mail: jlparre@uem.br 


\section{Introdução}

Para alcançar os objetivos almejados por este estudo, é de suma importância justificar a escolha do tema, as relações entre os agentes da cadeia produtiva e a importância da cultura no estado.

A cultura do feijão apresenta grande importância econômica e social no Brasil, visto ser este um dos alimentos básicos da população e o principal componente na dieta alimentar dos menos favorecidos. Além disso, de acordo com dados do Instituto Brasileiro de Geografia e Estatística (IBGE, 2004), o país é um grande produtor mundial desta leguminosa, que também é utilizada como alternativa econômica de exploração agrícola em pequenas propriedades, tornando-se uma renda e ocupação da mão-deobra menos qualificada.

Quanto à sua oferta, esta leguminosa — assim como os produtos agrícolas de abastecimento interno - sofre com a falta de incentivo do governo e a substituição por lavouras de exportação. Para Rodrigues et al. (2004), o crédito agrícola era centralizado em grandes produtores, o que proporcionou um hiato entre a renda dos produtores familiares e a dos comerciais. Assim, mesmo com o aumento da produtividade e a maior utilização de tecnologia, este produto teve crescimento insatisfatório em comparação às culturas destinadas ao mercado externo.

No entanto, apesar dessa deficiência, o Paraná ainda ocupa posição de destaque nos cenários nacional e regional. De acordo com o IBGE (2004), o feijão é a quarta cultura em área plantada no estado, cultivada principalmente em pequenos e médios estabelecimentos. Isso porque é uma das poucas alternativas para a absorção de mão-de-obra familiar e contratada, sendo responsável por uma parcela significativa da renda deste grupo. Em escala nacional, o Paraná é destaque como primeiro produtor, respondendo com 19\% da produção total do País (Figura 1). Contudo, apesar desses aspectos, existem poucos estudos sobre a economia de feijão, tanto no estado quanto no País, o que limita uma análise mais detalhada. 


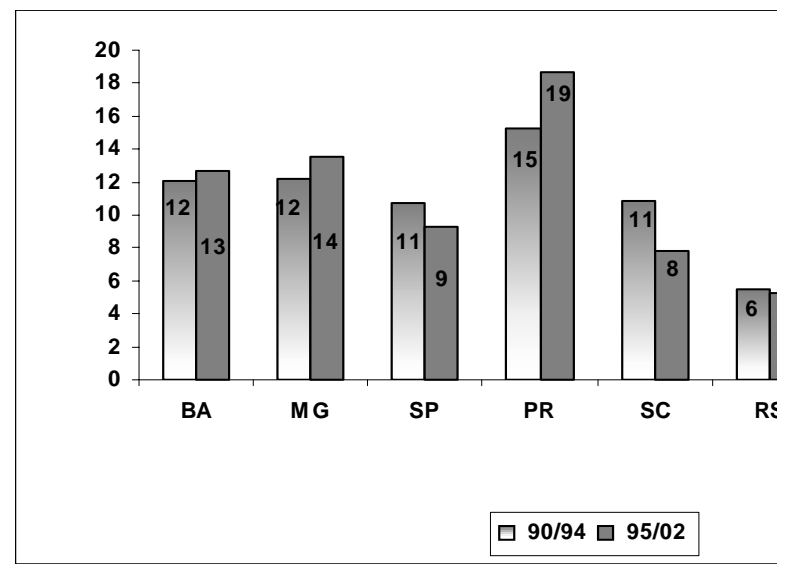

Figura 1 - Participação média dos principais Estados produtores de feijão no Brasil (90/94 - 95/02)

Fonte: IBGE/PAM - Produção Agrícola Municipal (1990/2002).

Já a sua comercialização no mercado interno ainda é instável, em razão da sua rápida perda de qualidade e da grande influência que exercem os "intermediários" na formação do preço final do produto. Segundo Carvalho Júnior \& Ozon (2004), o produtor ainda se ressente da falta de informações sobre a demanda do produto, facilitando as negociações em favor do setor de beneficiamento, em especial os grandes varejistas, aqui representados pelos supermercados. Isso porque, de acordo com Wilder (2003), o setor supermercadista investiu em tecnologias - como o uso de caixas eletrônicos e de cartões de fidelidade — que dão ao varejista um amplo acesso às informações de consumo e marcas específicas de cada faixa de renda, que pode ou não ser compartilhada com o fornecedor. Portanto, esse conhecimento proporcionado pelas novas tecnologias aumenta o poder de mercado do varejo.

Para Santos (2000), essa reestruturação, no tocante ao comportamento do setor de supermercados, se aprofundou na segunda metade dos anos 90, com o Plano Real, tendo em vista a estabilidade econômica gerada pela Política Monetária e a rápida expansão de consumo nos anos de 
1994 e 1995, quando foi reintegrada ao mercado consumidor uma parcela significativa da população. Também, a maior qualidade dos serviços prestados e a maior interação entre a indústria e o varejo para o lançamento de novos produtos são algumas das muitas vantagens.

No segmento produtor, segundo dados da Secretaria da Agricultura e do Abastecimento do Paraná (Paraná, 2004), houve ampliação de sua produção graças ao uso de melhor tecnologia, tanto no plantio (equipamentos mais modernos e, portanto, mais eficientes; sementes mais selecionadas) quanto no processo de armazenagem. Esses fatores levaram ao aumento da produtividade e à redução de custos de produção e armazenagem nesse segmento, com reflexos para o setor atacadista e, em especial, o varejista.

Por fim, considerando a posição do Paraná como produtor nacional e como quem abastece o mercado interno do Estado, bem como a identificação das demais características, buscou-se alcançar neste trabalho o conhecimento de como se processam as margens de comercialização nos três níveis de mercado, utilizando-as como indicadores de eficiência na distribuição e comercialização do feijão. Para isso, consideraram-se as variáveis relevantes nesse processo e a hipótese de liderança-preço na cadeia produtiva do feijão pelo setor varejista, em que a transmissão ocorre via ajustes parciais do varejo ao produtor.

\section{Metodologia}

\subsection{Modelo Teórico}

A concepção teórica básica para o desenvolvimento do trabalho será a teoria de margens de comercialização, a qual permite detectar as diferenças de preços nos três níveis de mercado (produtor, atacado e varejo) e, posteriormente, avaliar a transmissão de preços de um segmento do mercado para os demais. 
Para a análise das margens, utilizou-se a mesma abordagem feita por Aguiar et al. (1993), Aguiar (1994) e Ferreira (2001), de forma que serão estimadas como indicadores do grau de eficiência de mercado. Como exposto por esses autores, a margem pode ser apresentada de diversas formas, envolvendo todas ou apenas alguma das categorias de intermediários, bem como pode ser absoluta (em $\mathrm{R} \$ / \mathrm{kg}$ ) ou relativa (em relação ao preço no varejo). A interpretação do comportamento da margem absoluta permite verificar se os intermediários estão recebendo mais reais por unidade vendida. Esses acréscimos podem representar ineficiência, caso o produto não tenha sido melhorado ou não tenha havido aumento de preço de insumos de comercialização. A margem relativa, que é a participação no preço no varejo, permite analisar a distribuição do gasto do consumidor entre todos os agentes. Uma margem relativa decrescente pode decorrer de uso de poder de mercado, por outros níveis de mercado, ou de maior ganho de produtividade.

Contudo, algumas ponderações se fazem necessárias antes de analisar o assunto margens de comercialização. A indisponibilidade de estimativas de perdas de comercialização de feijão levou a adotar o procedimento de Ferreira (2001), que utilizou as diferenças de preços entre dois níveis de mercado como estimativa dessa margem. Como essas perdas existem e não podem ser negligenciadas, considera-se que as estimativas realizadas neste trabalho superdimensionam o valor exato da margem de comercialização desse produto. Ademais, as séries de preços não refletem os preços de um mesmo lote de produto, podendo apresentar diferentes origens e períodos. Entretanto, essas limitações não comprometem a validade dos resultados.

A seqüência deste trabalho dá-se com a apresentação do modelo econômico com causalidade Varejo $\rightarrow$ Produtor, proposto por Aguiar $(1994)^{4}$, para explicar o processo de transmissão de preços entre os níveis de mercado e o modo como se inter-relacionam. Isso porque é importante a apresentação de uma fundamentação teórica, no intuito de

Segundo o autor, uma característica dos modelos dinâmicos é a importância dada aos valores defasados ou expectativas de valores futuros de uma ou mais variáveis na explicação da variável dependente. 
dar credibilidade e consistência à análise empírica desenvolvida posteriormente.

A proposta da análise - que não difere do objetivo desse autor - é explicar o comportamento das margens em termos dos seus componentes internos, visto que fornecem informações pertinentes para a consecução das políticas públicas em prol de uma comercialização eficiente. Assim, o modelo baseia-se, essencialmente, no de Heien (1980) e Barros (1990), apresentando apenas os níveis de produtor e varejo. A estrutura básica considera os ajustamentos parciais e por excesso de demanda, admitindo, assim, a existência de desequilíbrios de curto prazo nos mercados. Já a utilização do markup como "preço-meta" por parte dos agentes de comercialização se torna uma prática preferível em situações de informação imperfeita.

Dessa forma, optou-se por esse modelo porque a sua possibilidade de sentido de causalidade entre os preços fornece instrumentos para a melhor compreensão do mercado em estudo. Assim, é importante ressaltar alguns aspectos desse produto que o enquadram no cenário do modelo proposto por Aguiar (1994).

O mercado de feijão paranaense possui três safras anuais, que já não podem ser consideradas distintas, podendo ele ser ofertado durante todo o ano. Como exposto anteriormente, a maior exigência por parte dos consumidores quanto à sua qualidade e aos ganhos de importância dos supermercados no seu fornecimento dá ao varejo a possibilidade de incrementos nas margens de comercialização quando este dá garantia da procedência e qualidade do feijão consumido. Ademais, como esse produto não possui mercado internacional dinâmico, com produtos de qualidade comparável ao doméstico, os intermediários tenderiam a acompanhar o desenvolvimento do mercado em nível de produção, o que leva a inferir que o mercado de feijão comporta-se como o modelo com causalidade Varejo $\rightarrow$ Produtor, no qual o primeiro nível teria um papel de liderança na constituição do preço. 
Para isso, admite-se que o preço varia inicialmente no varejo, mediante equação de excesso de demanda, e que essa variação ocorre em competição perfeita. Também se admite que o varejo opera com uma função de produção de proporções fixas (tipo Leontief): $V=\min \left\{\left(P / b_{1}\right),\left(Z / b_{2}\right)\right\}$, em que $\mathrm{V}$ é a quantidade do produto final ao varejo, $P$ é a quantidade de matéria-prima agrícola, $Z$ é a quantidade de um agregado de insumos de comercialização (armazenamento, transporte, processamento, etc.) e $b_{1}$ e $\mathrm{b}_{2}$ são os coeficientes técnicos de produção. Assim, as equações do modelo são:

\section{Mercado Varejista}

A demanda é uma relação linear do preço ao varejo:

$$
V_{t}^{d}=\theta_{0}+\theta_{1} v_{t} \quad \theta_{1}<0
$$

em que $V_{t}^{d}$ é a quantidade demandada ao varejo e $v_{t}$ é o preço ao varejo, ambos no instante t.

A oferta no varejo $V_{t}^{s}$ relaciona-se com a oferta agrícola $P_{t}^{s}$ por meio do coeficiente técnico de produção $b_{1}$ :

$V_{t}^{s}=\frac{P_{t}^{s}}{b_{1}}$

O ajustamento do preço ao varejo dá-se por excesso de demanda:

$$
v_{t}-v_{t-1}=\rho\left(V_{t}^{d}-V_{t}^{s}\right) \quad \rho>0
$$




\section{Mercado em nível de produtor}

A oferta em nível de produtor é uma relação linear do preço defasado ao produtor $p_{t-1}$ e do preço (exógeno) corrente de um agregado de insumos agrícolas ( )

$$
P_{t}^{s}=\gamma_{0}+\gamma_{1} p_{t-1}+\gamma_{2} c_{t} \quad \gamma_{1}>0 \text { e } \gamma_{2}<0
$$

Supõe-se que o "preço-meta" ao produtor seja aquele que leva o mercado varejista ao equilíbrio em competição perfeita, ou seja, é aquele que ocorre quando o varejo iguala seu custo marginal ao preço. Essa igualdade seria:

$C M a=b_{1} p_{t}^{*}+b_{2} z_{t}=v_{t}$.

em que $p_{t}^{*}$ é o preço-meta" do produtor, $\mathrm{z}_{t}$ é o preço do agregado de insumos de comercialização (exógeno) e $C M a$ é o custo marginal do varejista. Rearranjando os termos, tem-se:

$$
p_{t}^{*}=\frac{v_{t}-b_{2} z_{t}}{b_{1}}
$$

O ajuste do preço ao produtor dá-se por ajustamentos parciais:

$$
p_{t}-p_{t-1}=\alpha\left(p_{t}^{*}-p_{t-1}\right) \quad 0<\alpha<1
$$

Equações reduzidas dos preços

Substituindo a equação (6) na (7), tem-se:

$$
p_{t}=\frac{\alpha}{b_{1}} v_{t}+(1-\alpha) p_{t-1}-\frac{\alpha b_{2}}{b_{1}} z_{t}
$$


ou seja, o preço ao produtor se encontra positivamente relacionado com seu valor defasado e com o preço ao varejo e negativamente relacionado com o preço dos insumos de comercialização. Como o preço se forma ao varejo, aumentos de preço dos insumos de comercialização tendem a diminuir o preço ao produtor.

Substituindo a equação (4) na equação (2), chega-se à equação da oferta ao varejo. Substituindo essa equação e a equação da demanda (1) em (3), tem-se:

$v_{t}=\frac{\rho\left(\theta_{0} b_{1}-\gamma_{0}\right)}{b_{1}\left(1-\rho \theta_{1}\right)}+\frac{1}{1-\rho \theta_{1}} v_{t-1}-\frac{\rho \gamma_{1}}{b_{1}\left(1-\rho \theta_{1}\right)} p_{t-1}-$

Isso indica que um aumento no preço do insumo agrícola aumenta o preço ao varejo, em consequiência da menor oferta (agrícola e no varejo). Embora o preço do insumo agrícola afete, inicialmente, a oferta agrícola, este preço só se altera após a mudança no preço ao varejo.

Substituindo a equação (9), que já é a equação reduzida do preço ao varejo, na (8), chega-se à equação reduzida do preço ao produtor:

$$
\begin{aligned}
& p_{t}=\frac{\alpha \rho\left(\theta_{0} b_{1}-\gamma_{0}\right)}{b_{1}^{2}\left(1-\rho \theta_{1}\right)}+\frac{\alpha}{b_{1}\left(1-\rho \theta_{1}\right)} v_{t-1}+\left[(1-\alpha)-\frac{\alpha f}{b_{1}^{2}(1-}\right. \\
& -\frac{\alpha \rho \gamma_{2}}{b_{1}^{2}\left(1-\rho \theta_{1}\right)} c_{t}-\frac{\alpha b_{2}}{b_{1}} z_{t}
\end{aligned}
$$

\section{$\underline{\text { Margem de comercialização }}$}

A margem é dada por $M_{t}=v_{t}-b_{1} p_{t}$. Dessa forma, substituindo as equações (9) e (10) nesta última, obtém-se a equação reduzida da margem de comercialização: 


$$
\begin{aligned}
& M_{t}=\frac{\rho(1-\alpha)\left(\theta_{0} b_{1}-\gamma_{0}\right)}{b_{1}\left(1-\rho \theta_{1}\right)}+\frac{1-\alpha}{1-\rho \theta_{1}} v_{t-1}+\frac{(\alpha-1)\left[b_{1} \rho \gamma_{1}+b_{1}^{3}(]\right.}{b_{1}^{2}\left(1-\rho \theta_{1},\right.} \\
& +\frac{(\alpha-1) \rho \gamma_{2}}{b_{1}\left(1-\rho \theta_{1}\right)} c_{t}+\alpha b_{2} z_{t}
\end{aligned}
$$

Assim, o sinal esperado para o impacto do custo de comercialização sobre a margem de comercialização é que seja positivo. No entanto, o sinal do coeficiente do preço do insumo agrícola é inverso, ou seja, o seu aumento repercute positivamente sobre a margem de comercialização. Os sinais dos coeficientes defasados não podem ser antecipados; podem ser positivos ou negativos, dependendo dos sinais dos parâmetros que os compõem.

\subsection{Modelo Analítico}

Uma vez feita a abordagem teórica, o procedimento seguinte é desenvolver uma evidência empírica da relação de preços entre os diferentes níveis de mercado. Para isso, procura-se identificar o sentido de causalidade, ou seja, verificar em que setor se inicia a alteração de preços diante da ocorrência de algum fato. Com esse objetivo, aplicou-se o modelo Auto Regressivo Vetorial (VAR) desenvolvido por Sims (1972). Segundo o autor, esse modelo nada mais é do que um sistema de equações estimado com exatamente o mesmo conjunto de variáveis explicativas para todos os componentes da equação. Assim, se houver uma verdadeira simultaneidade entre conjuntos de variáveis, todas elas devem ser tratadas em pé de igualdade, não havendo distinção $a$ priori entre as variáveis endógenas e exógenas. Assim, tem-se: 


$$
\begin{aligned}
& z_{t}=\alpha_{0}+\sum_{i=1}^{k} \alpha_{i} z_{t-i}+\sum_{i=1}^{k} \beta_{i} y_{t-i}+\varepsilon_{I t} \\
& y_{t}=\beta_{0}+\sum_{i=1}^{k} \beta_{i} y_{t-i}+\sum_{i=1}^{k} \alpha_{i} z_{t-i}+\varepsilon_{I t}
\end{aligned}
$$

Uma forma bastante usual da aplicação do modelo é a análise de interrelações entre as variáveis. Nesse caso, existem duas formas específicas de utilizá-la, definidas como o teste de causalidade e a análise impulso reposta. Neste trabalho, o interesse restringe-se ao estudo das interrelações no que concerne ao efeito causalidade, considerando a relação de precedência temporal entre as variáveis.

Já a escolha do número de defasagens é arbitrária. Por um lado, é de fundamental importância assegurar a ausência de correlação serial nos termos de erros. Sendo assim, em conformidade com a abordagem econométrica, o número de defasagens $p$ foi escolhido pelo critério de defasagem distribuída ${ }^{5}$. Quanto à estacionariedade das séries, utilizaramse os testes de Dickey-Fuller, atentando-se para a possível transformação das variáveis não- estacionárias.

Para verificar se os parâmetros analisados são ou não iguais a zero, aplica-se o teste $\mathrm{F}$ para restrições conjuntas de que todos os parâmetros são estatisticamente iguais a zero ou de que não existe a relação de causalidade.

Assim, analisa-se se $z$ causa $y$ (no sentido de Granger) através do teste da hipótese de que os coeficientes de todas as defasagens de $z$ na equação de $y$ são conjuntamente iguais a zero. A hipótese nula de não-causalidade seria:

\footnotetext{
De acordo com Gujarati (2000), uma das características do modelo VAR é de que o número de defasagens para cada variável deve ser igual para todas as variáveis do modelo.
} 
$H_{0}=\alpha_{i}=\beta_{i}=0$, que é o teste-F usual de restrições lineares.

Neste caso, não é possível trabalhar com séries não-estacionárias, sendo recomendável utilizar as séries em diferença.

\subsection{Fonte de Dados}

Os dados utilizados na realização das análises das margens de comercialização e da transmissão de preços foram as séries mensais, relativas ao período de janeiro de 1995 a dezembro de 2003, a saber: (1) os preços $^{6}$ de feijão nos diferentes níveis de mercado (produtor, atacado e varejo) do Estado do Paraná, obtidos na Secretaria da Agricultura e do Abastecimento do Paraná (SEAB/DERAL, 2004); (2) o salário mínimo real como proxy do custo de comercialização (série em reais - $\mathrm{R} \$$ ), elaborada pelo IPEA, deflacionando-se o salário mínimo nominal pelo Índice Nacional de Preços ao Consumidor (INPC) do IBGE); (3) a taxa de juros ${ }^{7}$ (over/selic) como proxy dos custos de armazenamento, do Banco Central do Brasil. Todos os testes realizados no trabalho utilizaram o pacote econométrico Regression Analysis of Times Series- RATS versão 3.2.

\section{Análise dos resultados}

\subsection{Margem de Comercialização e Parcela do Produtor}

Analisando os dados da Tabela 1, sob a ótica de tendência geral do mercado em termos percentuais, revela-se uma estabilidade maior na margem relativa ao atacado, com decréscimos pouco significativos e

\footnotetext{
A série preços foi deflacionada pelo IGP-M (Índice Geral de Preços de Mercado) para janeiro de 2004, calculados e divulgados pela Fundação Getúlio Vargas. Nesse caso, a série utilizada corresponde ao feijão da classe cores; isso porque os trabalhos desenvolvidos nesta área utilizaram este tipo de feijão, que, certamente, é o mais consumido no País.

7 A escolha da taxa de juros (\% a.m), referência para os custos de oportunidade do capital, se dá pela importância atribuída a esta variável a partir do Plano Real como reguladora das decisões econômicas.
} 
acréscimo da margem de comercialização do varejo e produtor (embora com algumas oscilações no período), ocorrendo, no geral, uma troca da participação no preço final ao consumidor, entre produtor e varejo. Podese afirmar então que o nível de mercado varejista, entre os intermediários, tem-se apoderado das maiores parcelas dos preços finais dos produtos considerados neste estudo, o que não implica maiores lucros.

As margens absolutas de comercialização do atacado se comportaram com significativas oscilações, revezando-se entre quedas e picos, enquanto o varejo teve uma trajetória mais suave, apresentando acréscimos até 1998 e uma redução considerável em 1999 e 2000, estabilizando-se posteriormente. No geral, as margens absolutas dos varejistas são maiores que as dos atacadistas, justificadas tanto pelo lucro quanto pelo custo dos primeiros na apresentação do produto final ao consumidor. No entanto, verifica-se que o nível de mercado varejista do feijão provoca menor impacto sobre as margens totais, por apresentar uma trajetória mais suave. A tendência de crescimento da margem absoluta total se deve à influência da margem absoluta em nível de varejo, por esta apresentar comportamento mais estável.

Já as parcelas do produtor, como afirmado anteriormente, tiveram uma trajetória crescente, embora com oscilações, apresentando uma troca de posições com o varejo. 
Tabela 1 - Médias anuais das margens de comercialização, no período de 1995 a $2003^{8}$

\begin{tabular}{lccccccc}
\hline Margem & & 1995 & 1996 & 1997 & 1998 & 1999 & 2000 \\
\hline Atacado & Abs* & 0,465 & 0,581 & 0,476 & 0,831 & 0,549 & 0,38 \\
& Rel & 0,250 & 0,248 & 0,245 & 0,252 & 0,231 & 0,216 \\
\hline \multirow{2}{*}{ Varejo } & Abs* & 0,433 & 0,436 & 0,531 & 0,778 & 0,766 & $0,62 \epsilon$ \\
& Rel & 0,233 & 0,186 & 0,274 & 0,237 & 0,323 & 0,34 \\
\hline \multirow{2}{*}{ TOTAL } & Abs* & 0,898 & 1,017 & 1,006 & 1,609 & 1,315 & $1,01 c$ \\
& Rel & 0,483 & 0,434 & 0,519 & 0,489 & 0,554 & 0,55 \\
\hline
\end{tabular}

*Referência (reais/kg). Valores reais corrigidos para janeiro de 2004.

Obs.: Abs $=$ absoluta, Rel. $=$ relativa.

Fonte: Resultados do trabalho.

O aumento médio na margem de comercialização do varejo e na parcela do produtor no período em estudo está ligado, principalmente, à tendência de estabilidade no preço ao atacado, acompanhada de pequenos decréscimos, juntamente com o ganho de importância dos supermercados na distribuição de feijão, garantindo a qualidade do produto final. Considerando que a margem pode ser interpretada como a soma dos custos com os lucros ou prejuízos dos intermediários, esses acréscimos sofridos no varejo podem ser creditados ao aumento dos custos com a melhoria do produto, o que representa uma eficiência de mercado.

Ao contrapor os resultados das margens do mercado de feijão paranaense com os resultados encontrados por Aguiar et al. (1993), Aguiar (1994) e Ferreira (2001), o que se observa é a confirmação dos estudos anteriores no que concerne ao ganho cada vez maior do varejista na composição do preço final, em detrimento dos ganhos obtidos pelo atacado.

${ }^{8}$ Considerando que a Parcela do Produtor $(\mathrm{Pp})=1-\mathrm{MT}^{\prime}($ Margem Total Relativa $)$ 
Assim, tanto Aguiar et al. (1993) e Aguiar (1994) — analisando os preços de feijão no período de 80 e 90 para o Estado de São Paulo — quanto Ferreira (2001), durante a década de 1990 em nível nacional, concluíram que em nenhum nível de mercado ocorreu tendência explosiva desta variável. Mesmo com a liderança-preço garantida pelo setor atacadista, a margem deste agente mantivera-se estável num patamar inferior à margem dos varejistas. Cabe salientar também que Ferreira (2001) alertou em seu trabalho para a reestruturação vivida pelo varejo, representado pelos supermercados, e o possível impacto dessa mudança sobre a comercialização do produto. Ademais, esses autores constataram a rápida transmissão entre o atacado e os demais níveis, o que sugere um funcionamento adequado do mercado.

\subsection{Estudo Econométrico e Econômico}

A etapa seguinte foi a utilização do teste de causalidade, com a finalidade de analisar as relações entre as variáveis e comprovar ou não a tendência descrita por esses autores a despeito da importância do atacado na formação de preços de produtos agrícolas.

Assim, as variáveis foram analisadas aos pares, procurando-se verificar qual a direção de causalidade. Para isso, utilizou-se o critério de defasagem distribuída, considerando que as variáveis foram utilizadas em primeira diferença; isso porque, nos testes Dickey-Fuller, constatouse a presença de uma raiz unitária para todas as séries. Segundo o teste de causalidade, não foi possível constatar que o atacado seja o líder no mercado de feijão. Para esse mercado, a variável independente foi o varejo (var), o que contraria os trabalhos realizados com produtos agrícolas, que indicaram o setor atacadista como líder na formação de preços. Desse modo, por razões expostas anteriormente, o setor formador de preços para a cadeia produtiva de feijão do Paraná (1995/2003) é o varejo, conforme descrito na Tabela 2. 
Tabela 2 - Aplicação do modelo VAR para o teste de causalidade

\begin{tabular}{ccccc}
\hline \multicolumn{2}{c}{ VARIÁVEIS } & \multicolumn{2}{c}{ TESTE } & RESULTADOS \\
\cline { 1 - 4 } DEPENDENTE & INDEPENDENTE & $\mathrm{F}$ & SIGNIFICÂNCIA & \\
PROD & ATAC & 0,6191 & 0,4332556 & INDETERMINADO \\
ATAC & PROD & 1,3438 & 0,2491589 & INDETERMINADO \\
ATAC & VAR & 3,7937 & 0,0543084 & VAR $\rightarrow$ ATAC \\
VAR & ATAC & 1,8458 & 0,1773879 & INDETERMINADO \\
PROD & VAR & 9,6240 & 0,0024966 & VAR $\rightarrow$ PROD \\
VAR & PROD & 0,0064 & 0,9364252 & INDETERMINADO \\
\hline
\end{tabular}

Obs.: $\mathrm{PROD}=$ preço ao produtor, $\mathrm{ATAC}=$ preço no atacado, $\mathrm{VAR}=$ preço no varejo. Fonte: Resultados do trabalho.

Os testes de causalidade foram feitos com nível de significância de $10 \%$, e os resultados indicam o sentido predominante de causalidade do varejo sobre os demais níveis de mercado. Segundo trabalhos empíricos realizados por Barros (1990), Aguiar et al. (1993), Aguiar (1994) e Ferreira (2001), o resultado esperado seria o de que a variável independente fosse o atacado, ou seja, seria de se esperar que o atacado fosse o líder de mercado. Isso porque, segundo Barros (1990), os preços no mercado atacadista se ajustam instantaneamente e com baixo custo, além de as vendas serem centralizadas, de curto prazo, e possuírem maior especialização, com acesso facilitado às informações. Quanto às alterações de preços entre os produtores e o varejo, elas acontecem com uma certa defasagem, porque os primeiros estão pulverizados e trabalham com pequena quantidade do produto, enquanto o segundo não é especializado.

No entanto, os resultados encontrados endossam outros trabalhos, citados anteriormente, os quais mostram a importância crescente do setor supermercadista sobre o restante da cadeia produtiva. Assim, autores como Sesso Filho (2003) salientam a globalização como fonte que alimenta a concorrência e que leva os supermercados de grande porte a expandirem 
suas ações, gerando marcas famosas, como as de grandes redes, que estão na maioria dos países desenvolvidos e emergentes. As fusões e associações, combinadas à adoção de tecnologias, ao conhecimento da demanda e à exigência dos consumidores, facilitaram a adoção de estratégias e a liderança de preços deste setor perante os demais atores do processo produtivo.

Em seguida, apresenta-se, neste item, um modelo que propõe subsidiar mais claramente a análise empírica que foi conduzida. Para isso, optouse por utilizar, neste trabalho, o modelo de causalidade Varejo $\rightarrow$ Produtor, a fim de observar a transmissão de preços no mercado paranaense de feijão. A opção por este modelo decorre da semelhança entre as circunstâncias em que se baseia e o mercado em estudo.

Segundo esse modelo (Tabela 3), as variáveis que tiveram maior significância na sua determinação foram os preços ao produtor (prod) e ao varejo (var) defasados em um período. Entretanto, variáveis importantes, como os coeficientes da taxa de juros e salário mínimo, não tiveram um bom ajustamento. A taxa de juros (não-significativo) apresentou-se com o sinal negativo, reproduzindo o mesmo ajustamento visto em Aguiar (1994) para o mercado de arroz e feijão. O autor afirma que o sinal negativo pode ser interpretado como um reconhecimento de que o mercado financeiro é uma alternativa à estocagem de produtos agrícolas. Dessa forma, quando a taxa de juros aumenta, os indivíduos que detêm feijão estocado optam por vender parte do estoque. O salário mínimo, além de não-significativo, mostrou um sinal negativo não compatível com o modelo dinâmico com causalidade varejo $\rightarrow$ produtor.

Já o preço do varejo do período anterior mostrou um comportamento contrário, ou seja, significativo na determinação do preço recebido, mas com o sinal do seu coeficiente não compatível com as especificidades do modelo. Nesse caso, o principal determinante na formação do preço recebido foi o próprio preço do produtor. Isso pode ser justificado pelo fato de as oscilações de preço serem de curtíssimo prazo e pelo comportamento do produtor de buscar maiores informações do mercado, 
a fim de manter a tendência na participação. Cada vez mais, o produtor paranaense perde a condição de tomador de preços e otimiza as informações disponíveis, refletindo positivamente não só no planejamento de sua produção, bem como em toda a cadeia produtiva. Ademais, o coeficiente de determinação do modelo foi relativamente alto $(71,92 \%)$.

A forma estimada para representar a margem de comercialização mostrou que o coeficiente de varejo defasado foi positivo, sendo o único valor significativo a 5\%, ou seja, esse coeficiente demonstra uma relação direta entre o preço no varejo e a margem de comercialização no período seguinte.

Tabela 3 - Estimações do modelo dinâmico e da margem de comercialização total de feijão no Estado do Paraná, no período de 1995 a 2003

\begin{tabular}{ccc}
\hline Variáveis & Modelo Dinâmico & Margen \\
\hline Constante & 0,3692 \\
& $(1,47931)$ \\
\hline Prod od-1 & 1,1473 \\
& $(9.6594)$ \\
\hline Var $_{t-1}$ & $-0,2007$ \\
& $(-2.8818)$ \\
\hline Sal & $-0,000289$ \\
& $(-0,1204)$ \\
\hline \multirow{2}{*}{ Jur } & $-0,024716557$ \\
& $(-0,84643)$
\end{tabular}

Obs: entre parênteses, após os coeficientes, estão os valores do teste t.

Nível de significância: 5\%.

Fonte: Resultados do trabalho. 


\section{Conclusões}

A análise mostrou que o mercado do feijão tem-se comportado dentro de certos padrões de eficiência. O nível de mercado varejista, embora apresentasse liderança na transmissão de preços em relação aos demais níveis de mercado, condizente com o modelo no qual se baseou o estudo, geralmente não faz uso de poder de mercado, pois não tem apresentado tendência explosiva (o que em parte justifica os seus acréscimos como reflexo da melhoria do produto final).

Observa-se que a atuação do varejo na liderança-preço, bem como os seus ganhos de margens, é atenuada pela concorrência vivida nesse setor e pela exigência cada vez maior da ponta consumidora. Dessa forma, os resultados inferem que esses ganhos não revelam ineficiências ou perda de bem-estar, uma vez que não foi registrada a imposição de relações desvantajosas para os demais níveis de mercado e/ou para os consumidores finais. A reestruturação vivida por este setor reflete o momento de estabilidade econômica ocorrido no país e o novo perfil de consumo revelado.

No entanto, o nível de atacado, mesmo possuindo acesso facilitado às informações de mercado, manteve suas margens com tendência estável, e até decrescente, com os menores valores em relação aos demais.

Já o produtor, que aparentemente estabelece seus preços por markup, tem aumentado a sua parcela no mercado de feijão, podendo isso ser atribuído aos ganhos de produtividade usufruídos por este setor. Como afirmado anteriormente, o produtor paranaense, a cada safra, deixa de ser um tomador de preços e assume a postura mais racional de plantio.

Em suma, uma leitura que se pode fazer dos resultados é que o mercado em questão tem apresentado ajustes de preços relativamente rápidos e em magnitudes dentro do que se esperava teoricamente. Ademais, como mostrado em trabalhos de comercialização agrícola, a análise da liderança na transmissão de preços, isoladamente, não permite indicações sobre a 
eficiência dos mercados, pois um nível de mercado pode liderar a transmissão, sem que isso implique, necessariamente, ineficiência. Outros indicadores, como as margens absoluta e relativa, podem ser utilizados para aumentar o poder de análise sobre a eficiência de mercados.

\section{Referências}

AGUIAR, D. R. D. Custo, risco e margem de comercialização de arroz e de feijão no estado de São Paulo: análise dinâmica e teste de modelos alternativos. Piracicaba, 1994. 185p. Tese (Doutorado) Escola Superior de Agricultura "Luiz de Queiroz"/USP).

AGUIAR, D. R. D.; BARROS, G. S. A. C.; BURNQUIST, H. L.; FERREIRA, L.R. Análise da eficiência e competitividade no sistema de comercialização de feijão, In: Congresso Brasileiro de Economia e Sociologia Rural, 31, Ilhéus-BA, 1993. Anais, Brasília-DF, SOBER, vol. I, p.372-384, 1993

BARROS, G. S. A. C. Transmissão de Preços pela Central de Abastecimento de São Paulo, Brasil. Revista Brasileira Econômica. Rio de Janeiro, v.44, n.1, p.5-20, jan./mar. 1990.

BRASIL. Banco Central do Brasil. Boletim/Mercado Financeiro.

BRASIL. Instituto Brasileiro de Geografia e Estatística. Produção Agrícola Municipal: culturas temporárias e permanentes. Rio de Janeiro: FIBGE, 1990/2002.

BRASIL. Instituto Brasileiro de Geografia e Estatística. Rio de Janeiro: FIBGE, 2004.

BRASIL. Instituto de Pesquisa Econômica Aplicada. Dados Macroeconômicos e Regionais/IPEADATA. 
CARVALHO JÚNIOR, L. C; OZON, R. T. Análise das Transações e das Estruturas de Governança na Cadeia do Feijão da Região de União da Vitória (Pr), In: XLII Congresso Brasileiro de Economia e Sociologia Rural, 2004, Cuiabá (MT)

FERREIRA, C. M. Comercialização de feijão no Brasil 1990/99. Piracicaba, 2001. 145p. Dissertação (Mestrado) - Escola Superior de Agricultura "Luiz de Queiroz", Universidade de São Paulo.

GUJARATI, D. N. Econometria básica. São Paulo: Makron Books, 2000.

HEIEN- D. M. Markup pricing in at dynamic model of food industry. American Journal of Agricultural Economics, 62: 10-18. 1980.

PARANÁ. Secretaria da Agricultura e do Abastecimento. Departamento de Economia Rural. Acompanhamento da situação Agropecuária do Paraná, 2004.

RODRIGUES, R. V; CASTRO, E. R; TEIXEIRA, E. C. Avaliação de uma Política de Estabilização de Renda para Produtores de Mandioca, Leite e Feijão. In: XLII Congresso Brasileiro de Economia e Sociologia Rural, 2004, Cuiabá (MT)

SANTOS, E. V. dos. Análise das relações de preços entre estabelecimentos comerciais do setor supermercadista de Porto Alegre - RS. Porto alegre, 2000. 120p. Dissertação (Mestrado) - Curso de Pós-Graduação em Economia Rural, Universidade Federal Do Rio Grande Do Sul.

SESSO FILHO, U. A. O setor supermercadista nos anos 1990. Piracicaba, 2003. 185 p.Tese (doutorado) - Escola Superior de Agricultura “Luiz de Queiroz”, Universidade de São Paulo.

SIMS, C. A. Money, and causality. The American Economic Review, 62(4):540-552, 1972. 


\title{
WILDER, A. Mudanças no setor supermercadista e a formação de associações de pequenos supermercados. Piracicaba, 2003. 189p. Dissertação (Mestrado) - Escola Superior de Agricultura "Luiz de Queiroz", Universidade de São Paulo.
}

\begin{abstract}
Based in concepts and models of "commercialization", this work has as objective to analyze the transmissions of prices between producer, attacked and retail of the productive chain of the beans in the state of the Paraná, in the period of 1995/ 2003. For this, it was verified as the variable price was transmitted between the segments, esteem itself the edges and the causality direction enters the three sectors of market, that, together with the improvement of the final product, serve as indicating of efficiency in the distribution and commercialization of the product. In general way, the retail caused variations in the prices to the producer and attacked - causality confirmed for the application of model VAR - but that it did not represent an explosive trend of this variable. The study it discloses a trend of stability in the price the attacked one, followed of small decreases, together with the profit of importance of the supermarkets in the distribution of beans to the retail, guaranteeing the final product quality. The reorganization lived for this sector reflects the moment of economic stability occurred in the country and the new profile of the consumer.
\end{abstract}

Keywords: commercialization, transmission of prices, beans, Paraná. 